\title{
Diversidade Sexual, Situação de Rua, Vivências Nômades e Contextos de Vulnerabilidade ao HIVIAIDS
}

\author{
Marcos Roberto Vieira Garcia ${ }^{1}$ \\ Departamento de Ciências Humanas e Educação da Universidade Federal de São Carlos, \\ Sorocaba, Brasil
}

\begin{abstract}
Resumo
O presente artigo visa a refletir sobre os contextos de vulnerabilidade ao HIV/AIDS entre a população LGBT em situação de rua, a partir de pesquisa de campo que buscou analisar suas trajetórias de vida, realizada na região central de São Paulo. Foram realizadas 11 entrevistas semi-abertas com pessoas LGBT em situação de rua, sendo quatro delas com gays, duas com lésbicas, três com homens bissexuais, uma com uma travesti e uma com uma mulher transexual. A análise evidenciou a presença de uma forma de sociabilidade nômade, associada ao afastamento de vínculos com as instâncias trabalho, família e escola, à vivência nas ruas e ao uso frequente de substâncias psicoativas, relacionada ao preconceito heterossexista nas famílias, escolas e ambientes de trabalho, mas também à resistência aos ideais de fixação presentes nestas instituições. Em relação ao HIV/AIDS, este estudo mostra que a vida nas ruas configura-se como uma situação onde se acumula uma sinergia de situações de discriminação e violência que, fortemente relacionadas entre si, aumentam a vulnerabilidade à infecção pelo HIV, e ao mesmo tempo dificultam a vinculação aos serviços de saúde e a guarda da medicação antirretroviral utilizada, impedindo o tratamento adequado nos casos de adoecimento por AIDS.
\end{abstract}

Palavras-chave: População de rua, LGBT, HIV/AIDS.

\section{LGBT Homeless People, Nomadism and Contexts of Vulnerability to HIVIAIDS}

\begin{abstract}
This article aims to reflect on the contexts of vulnerability to HIV/AIDS among the homeless LGBT population, based on a field research that sought to analyze their life trajectories, held in Sao Paulo downtown. Eleven semi-structured interviews were conducted with homeless LGBT people, four of them with gays, two with lesbians, three with bisexual men, one with a transvestite and a one with a transsexual woman. Analysis showed the presence of a nomadic form of sociability associated with the removal of links with the work-places, family and school, living on the streets and the frequent use of psychoactive substances, related to heterosexist bias in families, schools and work-places, but also to resistance to the ideals of attachment present in these institutions. In relation to HIV/AIDS, this study shows that homelessness is characterized as a condition defined by a synergy of situations of discrimination and violence, strongly related to each other, that increases vulnerability to HIV infection, while hindering the linkage to health services and custody of antiretroviral medication use, preventing adequate treatment in cases of illness from AIDS.
\end{abstract}

Keywords: Homelessness, LGBT, HIV/AIDS.

Endereço para correspondência: Universidade Federal de São Carlos, Campus Sorocaba, Rodovia João Leme dos Santos (SP-264), Km 110, Sala 33, Itinga, Sorocaba, SP, Brasil 18052-780. E-mail: mrgarcia@usp.br Agências de Financiamento: Coordenação de Aperfeiçoamento de Pessoal de Nível Superior (CAPES) e Conselho Nacional de Desenvolvimento Científico e Tecnológico (CNPQ). 


\section{EI Nomadismo y Contextos de Vulnerabilidad al VIH/SIDA entre la Población LGBT en las Calles}

\section{Resumen}

En este artículo se pretende reflexionar sobre los contextos de vulnerabilidad al VIH / SIDA entre la población LGBT en las calles, con base en una investigación de campo que intentó analizar sus trayectorias de vida, que se celebró en el centro de Sao Paulo. Se realizaron 11 entrevistas semi-estructuradas con personas LGBT en las calles, cuatro de ellas con los gays, dos con las lesbianas, tres con hombres bisexuales, una con una travesti y una con una mujer transexual. El análisis mostró la presencia de una forma nómada de la sociabilidad asociada con la eliminación de los enlaces con el trabajo, la familia y la escuela, la vida en las calles y el uso frecuente de sustancias psicoactivas, en relación con el sesgo heterosexista en las familias, escuelas y los lugares de trabajo, sino también con la resistencia a los ideales de la fijación presente en estas instituciones. En relación con el VIH / SIDA, este estudio muestra que la vida callejera se caracteriza por ser una condición definida por una sinergia de las situaciones de discriminación y violencia, fuertemente relacionadas entre sí, que aumenta la vulnerabilidad a la infección por VIH, mientras que dificulta la vinculación con los servicios de salud y la custodia del uso de medicamentos antirretrovirales y la prevención de un tratamiento adecuado en casos de enfermedad de SIDA.

Palabras clave: Población en las calles, LGBT, VIH/SIDA.

O presente artigo visa a promover uma reflexão sobre os contextos de vulnerabilidade ao HIV/AIDS entre lésbicas, gays, bissexuais, travestis e transexuais (LGBT) em situação de rua, a partir de pesquisa de campo que buscou analisar suas trajetórias de vida, realizada na região central de São Paulo. Esta introdução apresenta primeiramente a bibliografia pertinente à população estudada, predominantemente produzida em outros países, e na sequência os temas das vivências nômades urbanas associadas às homossexualidades e do HIV/AIDS na população em situação de rua, importante para reflexões posteriores feitas no artigo.

A maior propensão de pessoas LGBT a se encontrarem em situação de rua e a especificidade de suas vivências nas ruas e instituições de acolhida, tema ainda pouco estudado em nosso país, é algo que vem sendo observado de forma consistente em estudos internacionais. Nos estudos sobre população de rua nos Estados Unidos, é comum o recorte nos estudos acadêmicos dos homeless youths, segmento que inclui os jovens de rua ou que vivem em abrigos e inclui em alguns estudos jovens adultos com idade próxima aos 30 anos. É este segmento que concentra a maioria das pesquisas estadunidenses voltadas às especificidades relacionadas à orientação sexual entre as pessoas em situação de rua. Nas grandes cidades da Costa Oeste norte-americana, a proporção de jovens que se identificam como LGBT em relação ao total de jovens em situação de rua se situa em torno de $20 \%$ (Cochran, Stewart, Ginzler, \& Cauce, 2002; Kennedy, 1991; Unger, Kipke, Simon, Montgomery, \& Johnson, 1997). O principal fator que explicaria esta elevada proporção seria o fato de os(as) jovens LGBT (lésbicas, gays, bissexuais e transgêneros) serem muito mais suscetíveis a serem expulsos(as) ou fugirem de casa em uma idade precoce do que os(as) heterossexuais, o que leva muitos(as) a viverem em abrigos ou nas ruas (Hyde, 2005; Rew, Whittaker, Taylor-Seehafer, \& Smith, 2005; Whitbeck, Chen, Hoyt, Tyler, \& Johnson, 2004).

A bibliografia norte-americana indica também algumas peculiaridades entre jovens homeless LGBT em relação àqueles que se identificam como heterossexuais: tem um histórico mais frequente de violência física e sexual na família de origem e também posteriormente, quando estão nas ruas (Whitbeck et al., 2004); são mais sujeitos ao abuso de álcool e substâncias ilícitas (Cochran et al., 2002); são mais sujeitos à discriminação por parte dos próprios colegas de rua e da polícia (Milburn, Ayala, Rice, Batterham, \& Rotheram-Borus, 2006); tem um número significativamente maior número de parceiros sexu- 
ais (Cochran et al., 2002); são praticantes mais frequentes do survival sex - troca de atividade sexual por drogas, alimentos, abrigo ou dinheiro (Whitbeck et al., 2004); são mais sujeitos a entrar no mercado da prostituição (Kruks, 1991; Pennbridge, Freese, \& Mackenzie, 1992); são mais vulneráveis à infecção pelo HIV (Kipke, O’Connor, Palmer, \& Mackenzie, 1995; Pfeifer \& Oliver, 1997; Rotheram-Borus \& Koopman, 1991; Sondheimer, 1992; Sugerman, Hergenroeder, Chacko, \& Parcel, 1991).

Em estudo conduzido na Inglaterra, Dunne, Prendergast e Telford (2002) observaram neste segmento o histórico comum de violência na infância, abuso de drogas, envolvimento com prostituição e escolaridade interrompida (muitas vezes motivada por bullying duradouro e intenso) e mostraram que para mais de um terço de seus pesquisados a questão da identidade sexual foi o "gatilho" para a crise familiar que precedeu a saída de casa. Já dois terços dos jovens LGBT em situação de rua australianos que participaram do estudo conduzido por Rosenthal, Mallett e Myers (2006) apontaram os conflitos com os pais como a única razão importante para deixarem o domicílio de origem.

As questões relativas à sexualidade têm sido trazidas à tona em alguns estudos brasileiros sobre a população de rua. Escorel (1999) cita relatos de dois de seus informantes que estimavam que $60 \%$ dos homens moradores de rua cariocas têm relações homossexuais, o que seria motivado pela "carência afetiva que sentem na rua e uma convivência quase que exclusivamente masculina" (p. 165), além da troca eventual de sexo por dinheiro. De Lucca (2007) em um estudo realizado parcialmente com observação participante dentro de um albergue masculino paulistano, refere, de passagem, que ali há muito "namoro e sexo, apesar de haver um forte preconceito contra homossexuais" (p. 218) e nota o barulho do sexo constante do dormitório masculino à noite. Frangella (2004), em pesquisa realizada no bairro do Brás, em São Paulo, observou a presença de homossexuais efeminados que "apareciam nas ruas e no refeitório, com certo destaque, porém de maneira discreta. Portavam brincos, os cabelos arrumados, alguns tratados com gel. Vestiam calças e camisetas justas, mas sem exagero" (p. 171). Apesar da estigmatização a eles direcionada em alguns momentos, observa que isto não impedia a convivência deles com os demais e que

os homossexuais compartilham as fogueiras, a pinga, a comida, e fazem parte de outras sociabilidades cotidianas da rua. São incluídos, inclusive, por meio de suas qualidades femininas: carinhosos, acolhedores, dóceis. Elas são incluídas na condição feminina, até no que diz respeito à satisfação sexual. Muitos homossexuais possuíam maridos na rua... Da parte dos homens, as manifestações da libido são... insinuantes quando associadas a seus companheiros homens ou homossexuais "de coberta" (p. 198).

A mesma autora observa, a exemplo de Escorel (1999), que a prática sexual homoerótica muito difundida (estimada pelo coordenador do refeitório onde fez a pesquisa de ser praticada por $80 \%$ das pessoas de rua dali usuárias) não significa a identificação por parte da maioria dos que a praticam como homossexual e que, na "ausência de mulheres, e embriagados sob a intimidade dos cobertores, homens cedem seus carinhos a outros homens, ainda que isso seja pouco assumido" (Frangella, 2004, p. 219).

\section{População de Rua, Homossexualidades e Vivências Nômades}

Alguns estudos no âmbito das Ciências Humanas que refletem sobre a questão do deslocamento de pessoas por diferentes espaços geográficos se utilizam do termo 'nomadismo' como uma categoria que transcende este mero deslocamento, tornando-se um modo de vida com características próprias e/ou como uma característica típica das vivências "pós-modernas". De fato, se considerarmos que o período atual corresponde a um período histórico de fragmentação das identidades de gênero, sexualidade, etnia, raça e nacionalidade, aquelas que mais eram definidoras da estabilidade social (Hall, 2003), os sujeitos tornam-se potencialmente mais livres frente às possibilidades de formação e rompimento de vínculos de todas as ordens e, portanto, mais móveis. Exemplos de argumentações que 
relacionam o nomadismo não somente ao deslocamento geográfico como também a um tipo de subjetividade estão presentes nas obras de Deleuze e Guattari (1995) e Maffesoli (2001).

Maffesoli (2001) refletindo criticamente sobre a concepção durkheiniana de anomia, considera esta condição como algo estrutural, não necessariamente negativa. O nomadismo aparece, dessa forma, como uma condição antitética em relação à sedentariedade, comprometida com as ideias de residência, segurança e domesticação. Condição por excelência da modernidade, a sedentariedade aparece como um desdobramento do Estado na vida cotidiana, onde o fixar aparece como um instrumento de dominação. Já o nomadismo, ao supor múltiplas identificações e, portanto, múltiplos lugares, configura um rompimento com este ideal moderno.

$\mathrm{Na}$ análise do nomadismo feita por Deleuze e Guattari (1995), este aparece de forma positivada, condição ligada à ideia de um futuro aberto, a ser construído sem um programa e relacionado à noção nietzschiana de "devir". No nomadismo o modelo de grupalização é o bando, que tem como algumas de suas características a ausência da consolidação de um poder estável, a transitoriedade e a rotatividade, o que faz com que seus integrantes se dissolvam e se reagrupem novamente. $\mathrm{Na}$ sedentariedade, por outro lado, ordem dominante na sociedade capitalista e que tem na família o modelo por excelência, os indivíduos são capturados espacial e identitariamente em organizações sociais mais definidas. $\mathrm{O}$ nomadismo aparece como uma possibilidade de heterogeneidade oposta à estabilidade e à constância, como uma linha de fuga à captura identitária típica do Capitalismo. Uma análise bastante instigante de Guattari (1992) considera que o Capitalismo cria também um "falso nomadismo", uma simulação com a finalidade de proteção frente ao nomadismo verdadeiro, processo que pode ser observado na vivência metropolitana, onde há aparentemente tudo circula (pessoas, carros, músicas, moda etc.), mas ao mesmo tempo tudo parece estar fixo e imóvel.

A questão do nomadismo tem sido também objeto de atenção nos estudos sobre a população de rua. Há, porém, dissenso em relação a se a pretensa liberdade que o acompanha é "real", no sentido de corresponder a um movimento de resistência frente às normatizações associadas ao vínculo com o trabalho ou com a família, ou se é ilusória, correspondendo a uma negação da possibilidade de manter tais vínculos (e não a resistência a eles). Escorel (1999), embora concorde que o nomadismo é uma característica marcante da população de rua - seja o que envolve a migração frequente de uma cidade para outra, seja o relativo ao deslocamento contínuo pelos espaços públicos da cidade - é bastante crítica em relação às análises que o relacionam como algo da natureza intrínseca da pessoa em situação de rua, como se isto fosse, em última instância, uma escolha e considera seu nomadismo muito mais como uma imposição da pobreza e dos fluxos de circulação das cidades. Neste sentido, a rua é vista por ela não como um espaço de liberdade, mas como o "o espaço do imprevisível, da insegurança e da vulnerabilidade, do perigo constante que espreita" (p. 185).

Consideramos importante aqui considerar que as vivências nômades podem ser entendidas no caso da população de rua como associadas a um duplo processo: de resistência frente aos ideais de residência, segurança, estabilidade e constância, mas também de vulnerabilidade frente às inúmeras formas de violência existentes neste contexto. Abordá-las a partir de um ponto de vista exclusivamente positivado, de um rompimento que subverte a disciplinarização dos corpos e subjetividades, ou negativado, baseado nas ideias de falta, carência ou sofrimento, implica um empobrecimento das possibilidades interpretativas de seu universo vivencial. Da mesma forma devem ser entendidas as vivências nômades associadas às homossexualidades.

A relação entre o nomadismo e as homossexualidades tem sido explorada por alguns autores. Perlongher (1987) já observava a presença do modelo de sociabilidade nômade entre os michês e outros personagens do mercado sexual masculino em São Paulo. O afastamento da família de origem e a vivência junto à "turma de amigos" é citada como frequente por Green (2000), em relação do universo homoerótico brasileiro da segunda metade do século XX. Parker (2002), em sua análise da migração LGBT pelo Brasil e mundo afora, mostra que a busca 
pela liberdade sexual não é o único motivo da busca pela "cidade grande", ainda que a fuga da vigilância nas cidades menores seja um fator também importante. A busca pela prosperidade e pela modernidade, também presente em outros grupos de migrantes, são fatores a serem ressaltados na migração sexual: mesmo que os indivíduos continuem pobres, a diversidade e a velocidade da vida nas grandes cidades são preferíveis para muitos homossexuais que vêm para elas.

Se o nomadismo é uma característica marcante tanto da trajetória de pessoas em situação de rua como de muitas que se relacionam de forma homoerótica, é pertinente considerar sua relação com as vivências das pessoas LGBT de rua aqui estudados. Mais importante do que pensar na "soma" dos fatores que o possibilitam, contudo, é pensar na forma como os fatores pertinentes a cada uma destas vivências se articulam na vida destas pessoas. Mais especificamente, refletir sobre as articulações entre tempos e espaços vividos por elas.

Ao refletir sobre o fortalecimento do modelo de família nuclear burguesa a partir do século XIX na Europa, Perrot (2009) traça um paralelo entre tal modelo de família e a condição sedentária. A centralidade da figura do "pai" na França oitocentista, autoridade que substitui a do rei no ambiente doméstico, mostra o equívoco de se considerar o espaço privado como de domínio das mulheres, uma vez o "pai" domina também a casa, mesmo estando fora dela. Ao mesmo tempo, porém, os homens jovens são progressivamente autorizados a viver um período de liberdade frente às exigências de constituição familiar, a "viver a juventude" antes de o casamento os sedentarizar. Tal "nomadismo institucionalizado" se dá para a autora mesmo entre homens jovens de camadas populares, momento em que se formam os primeiros grupos ("tribos") juvenis.

Perrot (2009) faz um paralelo interessante em relação ao nomadismo dos jovens e a boemia dos artistas na época - espaço de relativa aceitação para os naquele momento denominados pederastas - importante de ser aqui retomado por permitir reflexões acerca do lugar do lazer entre jovens LGBT. Para ela, tanto os jovens provisoriamente nômades quanto os artistas mais permanentemente boêmios têm em comum a inversão simétrica em relação à vida burguesa, que se dá em relação ao seu tempo (noturno), ao seu espaço (ruas e bares), ao seu tipo de moradia (incerta) e a sua moralidade (não baseada na fidelidade). Seriam esses pilares da "vida nômade urbana" tempo noturno, espaços abertos, moradia incerta e relações sem compromisso - comuns também em certas homossexualidades de camadas populares, como é o caso da população LGBT de rua?

\section{Agravos à Saúde e HIVIAIDS entre Pessoas LGBT em Situação de Rua}

A vivência em um universo onde são frequentes as situações de privação e violência, a alimentação inadequada, as condições de higiene precárias, a falta de privacidade, a exposição direta às variações térmicas e o imperativo da busca diária por recursos para sobrevivência leva a um aumento substancial da vulnerabilidade aos agravos da saúde da população em situação de rua como um todo. Entre as doenças prevalentes no Brasil nesse segmento, estão as doenças sexualmente transmissíveis, incluindo a AIDS, as doenças de pele, em especial as úlceras e dermatites, as doenças respiratórias, principalmente pneumonia e tuberculose, hipertensão arterial, além de distúrbios neuropsiquiátricos, em especial epilepsia, dependência química de álcool e outras substâncias psicoativas e psicoses (Carneiro, Nogueira, Lanferini, Ali, \& Martinelli, 1998; Costa, 2005; Lovisi, 2000; Silva, 2000). A maior prevalência de distúrbios mentais nesta população parece seguir a lógica do "círculo vicioso": alguns distúrbios, como as dependências químicas, deficiências mentais e psicoses são fatores predisponentes em relação à situação de rua, no caso de não haver um acompanhamento psicossocial adequado. Mas a situação de rua também contribui para o surgimento ou recrudescimento destes distúrbios, como aponta Dantas (2007).

Alguns estudos mostram peculiaridades deste segmento em relação aos cuidados com a saúde. Nos discursos dos profissionais de saúde entrevistados por Carneiro et al. (1998), um dos elementos levantados é o de as pessoas nesta situação só se reconhecerem como doentes se tiverem sua capacidade de locomoção pela cida- 
de abalada, uma vez que isto inviabiliza a sobrevivência, que depende do acesso aos locais de alimentação, distantes uns das outros em uma cidade como São Paulo. Dantas (2007) observa também que muitas delas só procuram tratamento médico em situações de emergência, o que inclui traumatismos, aparecimento de sintomas graves ou de estágios mais avançados de alguma enfermidade. Os tratamentos que requerem uma vinculação maior aos medicamentos e serviços de saúde, como são o caso dos que envolvem a tuberculose e a AIDS são especialmente dificultados neste segmento, o que leva a uma agudização destas doenças e a possível infecção de outras pessoas que vivem nas mesmas condições.

A população em situação de rua no Brasil, a exemplo dos homeless norte-americanos, tem sido apontada como bastante vulnerável à infecção pelo HIV, justamente pela amplificação da situação de miséria econômica que nela observamos, fato que soma ao abuso comum de substâncias psicoativas, à falta de moradia fixa e à marginalização e à violência a que está submetida (Malta, Petersen, Clair, Freitas, \& Bastos, 2005). Pesquisas brasileiras recentes têm apontado uma maior prevalência do HIV/AIDS nesta população. Brito, Parra, Facchini e Buchalla (2007), em pesquisa feita com usuários de um albergue noturno em São Paulo detectaram prevalências de $8,5 \%$ de vírus de hepatite $C$, $30,6 \%$ de infecção pregressa por hepatite $\mathrm{B}, 3,3 \%$ de infecção aguda ou crônica pelo vírus hepatite $\mathrm{B}$, $5,7 \%$ de sífilis e de 1,8\% de HIV - índice mais de três vezes superior ao da população adulta brasileira, estimada em 0,5\% (Joint United $\mathrm{Na}$ tions Programme on HIV/AIDS [UNAIDS], 2006). No Primeiro Censo Nacional e Pesquisa Amostral sobre a População em Situação de Rua (Meta Instituto de Pesquisa de Opinião, 2008), $1,5 \%$ dos entrevistados afirmaram ser portadores de HIV/AIDS. Considerando-se que muitas pessoas não sabem que são portadoras e o estigma associado a se assumir como portador, este número é certamente subestimado.

\section{Metodologia}

A população abordada no estudo qualitativo foi composta por pessoas em situação de rua que se identificaram como LGBT ou termos correlatos, como, por exemplo, "homossexual", identidade mais autorreferida em camadas populares. O trabalho de campo começou com uma etapa inicial de mapeamento dos locais frequentados por este segmento da população de rua. Este mapeamento foi facilitado pelo fato de uma das pesquisadoras envolvidas ter sido agente comunitária em um programa na área de assistência social na região central de São Paulo, conhecendo estes locais de concentração. Devido ao fato de o trabalho de campo ter sido realizado no período de inverno, que faz com que as pessoas em situação de rua permaneçam mais em espaço fechados como forma de se proteger do frio, houve dificuldade em contatar possíveis informantes para a pesquisa diretamente nas ruas, em seu local de estadia ou moradia provisória. Por este motivo, optou-se pela realização de entrevistas em albergues, como forma de metodologia de campo alternativa. Em virtude da maior abertura para a realização desta parte da pesquisa de campo, foi selecionado um albergue da região central de São Paulo ao qual foi solicitada formalmente a autorização para a realização da pesquisa com seus usuários.

Foram realizadas 11 entrevistas, de tipo semi-aberta, mediante consentimento livre e esclarecido, sendo quatro delas com gays, duas com lésbicas, três com homens bissexuais, uma com uma travesti e uma com uma mulher transexual, categorias estabelecidas por agrupamento das autoidentificações dos sujeitos da pesquisa (os que se autoidentificaram como homossexuais foram agregados na categoria "gay" ou "lésbica"). A idade dos entrevistados variou entre 20 a 39 anos. O convite para a entrevista foi feito com base no conhecimento prévio de alguns pela pesquisadora citada, pela indicação de uma funcionária do albergue e pela sugestão feita pelos primeiros informantes entrevistados.

As entrevistas seguiram o seguinte roteiro: as relações com a família de origem na infância, o processo de escolarização, o relacionamento comunitário (com vizinhos, etc.) na infância, as eventuais experiências sexuais precoces, a inserção no mundo do trabalho e histórico profissional, crises e eventuais rompimentos com a família de origem, vida afetiva e sexual na ado- 
lescência e no presente, o uso e abuso de substâncias lícitas e ilícitas, os vínculos de amizade e redes de sociabilidade desenvolvidas desde a adolescência, as formas de lidar com o desemprego e estratégias de sobrevivência, o recurso a entidades assistenciais, os cuidados em relação à saúde, a prática (ou não) do sexo seguro, o relacionamento com outros segmentos da população de rua, o recurso a atividades ilícitas como estratégia de sobrevivência.

As entrevistas tiveram como estratégia o estabelecimento de um diálogo efetivo com a população estudada, maximizando o contexto relacional e interativo na obtenção dos dados, por meio de uma relação horizontal e uma postura de respeito com os sujeitos da pesquisa, como forma de se investigar as trajetórias de vida dos entrevistados. As entrevistas foram gravadas e transcritas.

A pesquisa foi aprovada por Comitê de Ética em Pesquisa em Seres Humanos da Universidade Federal de São Carlos (UFSCar) e seguiu os parâmetros éticos exigidos nas pesquisas com seres humanos, conforme a Resolução $\mathrm{n}^{\circ}$ 196/96, do Conselho Nacional da Saúde, o que inclui a devida documentação do consentimento livre e esclarecido dos envolvidos (entrevistados e instituição que frequentam) e os cuidados com seu anonimato.

Como proposta de análise dos dados foi utilizada a análise categorial de conteúdo segundo a proposta de Bardin (2004), que se caracteriza pela classificação dos elementos a serem analisados por uma diferenciação temática e um reagrupamento subsequente pela analogia estabelecida entre eles. A categorização permite, desta forma, condensar os dados brutos em representações mais simples, o que permite estabelecer inferências e interpretá-los. Está ligada à ideia, portanto, de busca de uma maior visibilidade dos dados, facilitando o trabalho de relacioná-los ao referencial teórico. O trabalho de análise buscou identificar os elementos comuns nas trajetórias dos sujeitos da pesquisa, de forma a configurar a trajetória social do grupo em questão. Foram considerados elementos importantes desta trajetória: as relações com a família de origem na infância, o processo de escolarização, as eventuais experiências sexuais precoces, a percepção dos desejos homoeróticos, os possíveis conflitos advindos desta percepção, a inserção no mundo do trabalho e histórico profissional, eventuais crises e rompimentos com a família de origem, vida afetiva e sexual na adolescência e no presente, o uso e abuso de substâncias lícitas e ilícitas, os vínculos de amizade e redes de sociabilidade desenvolvidas desde a adolescência, as formas de lidar com o desemprego e estratégias de sobrevivência, o recurso a entidades assistenciais, os cuidados em relação à saúde, a prática (ou não) do sexo seguro, a interação com outras pessoas LGBT de rua, o relacionamento com outros segmentos da população de rua, o recurso a atividades ilícitas como estratégia de sobrevivência, as vivências de discriminação relacionadas à orientação homo ou bissexual ou às identidades transgenéricas.

\section{Resultados e Discussão}

\section{Trajetórias de Vida}

Os conflitos familiares relacionados ao rompimento com o padrão heteronormativo foram apontados como determinantes para a situação de rua por parte significativa dos informantes da pesquisa. Este afastamento foi vivido por alguns de forma direta - sob a forma de expulsão pura e simples - e por outros de forma indireta, sob a perspectiva de que o assumir-se decepcionaria os familiares, o que acabou por gerar o afastamento dos mesmos:

"Os pais não conseguem entender, porque não é uma coisa, que assim, não é normal aos olhos dos outros, porque só quem tá ali no mundo GL que sabe como que é o bagulho, as pessoas que não tá, não consegue imaginar" (Wilson, bissexual, 20 anos).

"Pra mim eu tava passando uma coisa negativa na minha família. Acho que a minha mãe não se sentia bem porque eu era homossexual... ai, eu quis ir embora" ( $\mathrm{Nega}^{2}$, gay, 32 anos).

O afastamento da família de origem foi relacionado pelos informantes à falta de apoio fa-

2 O nome social original de Nega também faz alusão à afrodescendência. 
miliar em situações de instabilidade financeira, o que por sua vez foi visto como um fator determinante para a situação de rua atual. Em dois dos casos, a situação de morte dos pais levou a família a um descompromisso em relação a este apoio, motivado pelo preconceito em relação à homo/bi/transexualidade por parte do familiar:

"Meus tios venderam a casa [do pai do entrevistado, que faleceu] e sumiram... chegaram um dia com o cara que comprou e falou: 'Olha, você não é mais dono da casa, nem a gente, essa casa é dele, você esta na rua, e a gente não vai te ajudar por você ser homossexual"' (Tirso, bi, 22 anos).

"Família é pai e mãe, então quando o pai e a mãe falece, ai sim a situação fica mais complexa, porque nenhum parente vai querer se envolver mesmo... que insistentemente a gente manifeste, fale que esta morando na rua, mas as pessoas preferem não participar. Entrevistador: Você acha que isso teve a ver com ofato de você ser trans? Mariana: Tem, tem a ver sim" (Mariana, mulher transexual, 37 anos).

A investigação da trajetória escolar revelou também cenas frequentes de discriminação sofrida pelos informantes da pesquisa, ainda que estas algumas vezes não fossem claramente relacionadas por eles como fruto do preconceito:

"Na escola era aquela história 'MariaJoão'. Eu nunca gostei de ir à escola, muitas vezes eu brigava com os meninos fisicamente, tinha agressões fisicas e trocas de ofensas e aquilo me deixou machucada" (Luísa, lésbica, 22 anos).

"Na escola eu nunca consegui uma turminha pra mim, porque eu era vergonhoso e porque quando eu colava, os moleque tirava... 'ah, porque você é gay', eu ficava doido, não gostava mesmo" (Wilson, bi, 20 anos).

A trajetória profissional dos informantes apareceu também marcada pelo contexto do heterossexismo nos ambientes de trabalho, especialmente nos casos em que as performances de gênero fossem sugestivas de uma possível homossexualidade. Aqueles que conseguiam manter uma "aparência" heterossexual conseguiam driblar a discriminação nestes contextos, o que para alguns era vivido como um processo por vezes doloroso de assumir uma aparência heterossexual:

"Graças a Deus eu não pareço gay. Realmente para mim seria muito mais fácil arrumar um emprego" (Rogério, bi, 29 anos). "Eu não posso pedir o serviço, porque ela [empregadora] vai olhar pra mim e vai dizer: 'Como uma senhora lésbica vai trabalhar no meio de um monte de mulheres?'. Então eu tenho que fazer aquela transformação. Isso é muito ruim, eu não posso ser $e u$ " (Elaine, lésbica, 38 anos).

"Eu não posso procurar trabalho de jeans e camiseta, tenho que por roupa de patricinha. Eu não gosto, me incomoda, mas é assim que tem que ser... eu trabalhei como estagiaria uma vez, minha patroa falava: "não vem igual a um homem totalmente", (Luísa, lésbica, 22 anos).

A inserção no mercado sexual, seja de forma ocasional, seja por períodos mais longos, também foi citada por vários informantes e relacionada à dificuldade de se obter outro tipo de ocupação:

Entrevistadora: "Você veio aqui [para São Paulo] já pensando em fazer programa ou..."

Nega: "Não, infelizmente a única opção minha que teve foi essa, né?" (Nega, gay, 32 anos).

"Foram três homens que não eram do convívio, eram playboys, um termo da gíria, $e$ vieram de fora, jogaram um português claro, fizeram uma pergunta direta, falaram o preço. Eu não tinha dinheiro, não tava a fim de roubar, porque eu já roubei várias coisas, e eu aceitei" (Luísa, lésbica, 22 anos).

Por outro lado, o mercado do sexo se mostrou, para alguns dos informantes, também um recurso para se vivenciar a sexualidade sem os constrangimentos impostos por muitas das demais ocupações:

"Dai depois, no dia a dia, acabei se conhecendo se envolvendo, porque na rua lá aonde que eu trabalhava [como segurança] no centro, tinha o pessoal que andava de carro, e ai me pegava e eu acabei trocando o meu emprego normal, por esse mundo gay, 
saindo com pessoas no carro" (Rogério, bi, 29 anos).

É necessário relativizarmos, contudo, a relação de causa-efeito aparente entre estigmatização das homossexualidades e dificuldade de empregabilidade. A experiência de trabalho em profissões onde a homossexualidade seria mais tolerada também foi citada, o que mostra que existem campos de trabalho - em especial os relacionados à estética - onde alguns homossexuais efeminados conseguem trabalho e eventualmente até mesmo certa valorização por sua condição:

"Na minha profissão até pedem que seja homossexual, que é cabeleireiro... valoriza mais" (Tobias, gay, 39 anos).

Se considerarmos o tripé família, escola e trabalho como algumas das instituições socializadoras fundamentais dos indivíduos em nossa sociedade e que os indivíduos que manifestam suas homo/bi/transexualidades de forma ostensiva podem ser colocados às margens ou mesmo expulsos indiretamente de tais instituições, podemos afirmar que tal processo leva a uma dissolução dos laços sociais que correspondem mais fortemente ao processo de sedentarização em nossa sociedade. Abre-se, pari passu, a possibilidade de novas formas de sociabilidade calcadas em diferentes tempos (noturno), espaços (ruas e bares), tipo de moradia (incerta) e moralidade (não-monogâmica), características da vida nômade urbana descrita anteriormente.

$\mathrm{O}$ afastamento das instituições escolares e laborais acompanha de perto o afastamento das famílias de origem, algo que pode ser acentuado pelo heterossexismo no contexto familiar, e o ingresso em grupos de amigos que compartilham os mesmos valores, que assumem um lugar fundamental de suporte para uma vivência tida como desviante.

A vivência próxima a grupo de amigos possibilita as vivências das sexualidades dissidentes, longe da vigilância dos olhares vigilantes da família, como foi apontado anteriormente (Parker, 2002). Mas não somente o exercício da sexualidade mais "livre" surge em função deste afastamento: outras vivências tidas como desviantes são também por ele facilitadas, em especial o uso de substâncias psicoativas. Estas aparecem tendo seu uso frequentemente associado ao exercício das sexualidades, numa conexão aparente de busca de intensificação dos prazeres dos dois tipos, que se interseccionam:

"Não, eu nunca fui muito de, não vou falar que eu nunca, eu fui assim, eu tinha uns relacionamentos loucos, mas não de fazer assim, era mais de beijos, esses negócios de balada. Eu fumava um e tava loucão na balada, e na cachaça. Ai eu ficava muito louco com os meus amigos, e agente saia da bala$d a "$ (Wilson, bi, 20 anos).

"As vezes que eu dormi na rua foi só aquelas vezes, quando tava bebendo, tava na farra, não assim porque não tinha outra opção. Se eu tô a fim de alguém e a pessoa tá na rua eu também fico na ru" (João, gay, 32 anos). "Quando você usa o crack é foda, aí você sai com qualquer um. Quando você usa a droga, se você está sozinho, você sai. É que pelo menos comigo, a droga me dá tesão, entendeu?" (Tobias, gay, 39 anos).

As vivências associadas ao uso de drogas são apresentadas como marcadas por momentos de uso intenso, associados a um "perder-se de si mesmo" e de abstinência ou pouco uso, associados a um "controle de si mesmo". Como vimos anteriormente, Maffesoli (2001) define a antinomia nomadismo-sedentarismo como atrelada ao mesmo tempo à necessidade de segurança e ao desejo de um desligamento, desejo este que envolve rupturas de qualquer ordem. Os momentos de uso intenso e pouco uso/abstinência de drogas podem, portanto, ser entendidos dentro do mesmo processo de alternância entre sedentarismo e nomadismo. Passa a haver para muitos LGBT uma associação inversa entre este universo orgiástico e a vida sedentária, relacionada ao tripé escola/família/trabalho: quanto mais se mergulha na vida nômade, mais difícil a manutenção das relações tradicionalmente vividas naqueles contextos:

"Assim, porque eu comecei a conhecer a balada, esses negócio. Comecei a perder, tipo, comecei a ficar rebelde" (Wilson, bi, 20 anos).

Além da entrada nesse universo orgiástico, outros fatores apareceram como relevantes para entender o envolvimento com drogas ilícitas e 
que podem estar relacionados às homo/bi/transexualidades. Um deles refere-se à presumida maior frequência a bares e boates como forma de busca por relações de amizade ou afetivo-sexuais, devido à situação de discriminação sofrida e dificuldade de aceitação por parte das famílias, o que facilitaria o uso abusivo de álcool e outras substâncias psicoativas, frequentes em tais espaços:

"Eu comecei a trabalhar numa boate gay, fiquei um ano trabalhando e foi lá que eu conheci a cocaina. Dai eu me envolvi... Cheirando todo dia, porque fazia parte da rotina da noite, casa noturna, você sabe como funciona esse meio, né?" (Rogério, bi, 29 anos).

O abuso de substâncias psicoativas ${ }^{3}$ apareceu também como relacionado ao estigma associado às homo/bi/transexualidades, seja para mitigar o sofrimento pela discriminação sofrida ou como forma de diminuir a autocensura pela própria orientação sexual, em função da interiorização deste estigma:

"Dessa angústia que eu tinha dentro de mim que eu não conseguia saber por que eu não sentia orgasmo por homem, por que o meu marido me tocava e eu tinha nojo, tinha revolta entendeu? Então aí eu fugia dele e ficava quatro, cinco dias na rua me drogando e voltava e ai ficava essa vida, assim doida" (Elaine, lésbica, 38 anos).

As trajetórias dos informantes mostram que a homo/bi/transexualidade e o uso substâncias psicoativas se entrelaçam em suas vidas, articulando-se com e contribuindo para a sociabilidade

Estudos norte-americanos estimam que a população LGBT tem uma propensão maior de abuso de drogas ilícitas, com um incidência de duas a três vezes maior se comparada à população heterossexual de mesma idade e faixa de renda (Bux, 1996; Jordan, 2000). No Brasil, Terto (2002), considera que "é pouco conhecido como os efeitos do estresse de viver numa sociedade com tantos preconceitos contra a homossexualidade afetam a saúde psíquica e física dos homossexuais", o que demanda estudos locais "sobre como a depressão, atitudes destrutivas e uso de drogas, entre outros, estão relacionados às dificuldades de viver uma orientação sexual diferente da dominante". nômade anteriormente citada, baseada na vida noturna, na ocupação de espaços públicos, na saída das proximidades da família de origem e em vínculos afetivos eventuais.

Novamente é importante ressaltar que tais trajetórias não podem ser avaliadas a partir de um ponto de vista de valorização da residência, da segurança e da permanência dos vínculos, sob o risco de se considerar a vivência destas pessoas a partir de um conceito de erro ou desvio. Cabe lembrar que foi justamente este ponto de vista que possibilitou o estabelecimento das políticas hegemônicas de intervenção junto à população em situação de rua, calcadas na necessidade de se "sedentarizá-las" em torno da ideia de moradia e trabalho fixos, o que é compartilhado tanto pelas políticas que priorizam o controle disciplinar de forma explícita (higienistas) quanto por algumas políticas calcadas no reconhecimento dos direitos humanos da população de rua, que incluem a luta pelo direito ao trabalho e à moradia como essenciais.

Se o reconhecimento do direito à sociabilidade nômade das pessoas LGBT em situação de rua é fundamental, também o é o reconhecimento das múltiplas vulnerabilidades que atravessam seu cotidiano, ambos os movimentos presentes e em constante tensão nas concepções multiculturais dos direitos humanos bem resumidos por Souza Santos (1997) em sua conhecida afirmação de que "as pessoas e os grupos sociais têm o direito a ser iguais quando a diferença os inferioriza, e o direito a ser diferentes quando a igualdade os descaracteriza" (p. 122). Dentre estas vulnerabilidades, algumas apareceram como frequência no trabalho de campo, como é o caso da vulnerabilidade à violência e aos agravos da saúde. Pelo tema do presente artigo, contudo, será focado aqui um dos possíveis agravos à saúde deste segmento da população de rua: o relacionado à infecção pelo HIV/AIDS.

\section{Vulnerabilidade ao HIVIAIDS}

Os resultados da pesquisa confirmaram as hipóteses baseadas na literatura pesquisada que apontavam para um forte aumento da vulnerabilidade ao HIV/AIDS neste segmento, especialmente se atentarmos para o plano social da 
vulnerabilidade - que está relacionado a fatores como o desrespeito aos direitos humanos, incluindo o direito à escolarização e ao trabalho, o contexto político e cultural marcado pela discriminação e violência, a dificuldade de moradia adequada e de acesso a bens de consumo (Ayres, França, Calazans, \& Salleti, 1999), fatores estes onipresentes nas trajetórias dos informantes da pesquisa. O recurso ao mercado sexual e o abuso de drogas como consequência do processo de discriminação sofrida apontam também para um aumento da vulnerabilidade em seu plano social.

Entre os entrevistados, cinco referiram espontaneamente serem portadores do HIV ou já terem desenvolvido AIDS, mesmo não sendo este um tema abordado diretamente na entrevista. Os demais seis entrevistados não foram inquiridos sobre o tema e não relataram seu status sorológico. Todos os informantes portadores do HIV acreditam terem se infectado pela via sexual. Em um dos casos (Tobias, gay, 39 anos), é possível conjecturar sobre esta infecção ter ocorrido anteriormente à situação de rua, já que ele relatou ter tido um companheiro fixo por vários anos que faleceu vitimizado pela AIDS e com o qual teve relacionamentos sexuais desprotegidos. Nos demais casos, não foi possível fazer conjecturas neste sentido.

A descoberta de ser portador do HIV ou ter AIDS e a relação com o estar em situação de rua entre eles pode ser interpretada pela mesma perspectiva do "círculo vicioso" citado anteriormente: a situação de rua aparece como direta ou indiretamente responsável pela infecção e o aparecimento da doença, ao mesmo tempo em que o impacto emocional desta descoberta aparece como fator predisponente a se continuar em situação de rua, como pode ser percebido em algumas falas:

"Ai me adoeci. Fiquei 40 dias numa cama.

Eu sou uma pessoa que tem o porte de 90 $\mathrm{kg}$, eu pesei $45 \mathrm{~kg}$. Daí passei por um hospital, passei por outro. Sempre disseram a mesma coisa pra mim, mas eu pensava internamente que não poderia ser aquilo. Eu não podia comer, era uma diarreia, eu comia e corria pro banheiro. Daí foi quando eu encontrei uma médica, ela me falou: 'Eu vou fazer o exame de DST em você'. Eu disse, 'Tudo bem, pode fazer'. Ai pronto. Ali que foi, eu tinha conhecido a droga, ali eu me afundei. Levei aquele baque, porque perdi meu marido, perdi minha mãe, agora essa doença? Que mais que me resta? Mais nada. Dai tudo que eu tinha acabou. Definhou" (Antônio, gay, 30 anos).

"É só que eu descobri depois, eu fiz uns três exames porque eu não tava acreditando que eu estava. No dia que eu descobri que eu estava com HIV e hepatite B junto, eu cai em depressão, fiquei meio sem saber o que fazer" (Rogério, bi, 29 anos).

"Eu também fiquei um pouco adoentado, né. Eu tenho um problema de saúde, também fiquei adoentado. Eu tenho problema de HIV, tenho há nove anos HIV, ai eu comecei... Fiquei um pouco depressivo, aí cai nas drogas, fui usar crack, ai comecei a ficar doente" (Nega, gay, 32 anos).

As dificuldades de tratamento relacionadas à falta de vinculação com os serviços de saúde e com a guarda da medicação antirretroviral, descritas na bibliografia, também apareceram de forma incisiva nos relatos:

"Olha, eu vou ser sincero, eu comecei a fazer o tratamento e parei. Eu acho que eu tenho que voltar. Por enquanto eu tô bem" (Rogério, bi, 29 anos).

"Entrevistador: Você conseguia fazer o tratamento direito? Tobias: Quase, tinha dias que não. Entrevistador: Aconteceu de perder remédio? Tobias: Já. Entrevistador: Morar na rua atrapalha por quê? Tobias: É horrivel, não tem lugar para guardar, tem remédio que vai na geladeira. Agora não, agora eu já estou mais... Entrevistador: Você fazia como, você deixava no albergue? Tobias: Sempre ando na bolsa, eu tenho a minha mochila, sempre tá junto. Entrevistador: $E$ esse de geladeira? Tobias: Eu nunca usei o de geladeira. No começo eu tomava trinta comprimidos por dia, hoje eu tomo dois. Você pode ver que diminuiu bem. Entrevistador: Você acha que a situação de rua então atrapalha o tratamento? Tobias: Muito, nossa. Eu tô doido para sair dessa situação de rua, eu vou sair, cara, se Deus quiser" (Tobias, gay, 39 anos). 
"Entrevistador: Você parou de usar o remédio? Nega: Na rua. Ai eu fui medir o CD-4, o CD-4 tinha que ta trezentos e cinquenta, o meu tá quatrocentos e oitenta. A médica falou: 'Nossa, eu nunca vi um CD-4 desse, tão alto'. Ela falou: 'Olha, o Ministério da Saúde agora tem uma pesquisa para pessoas com HIV e tenham o CD-4 menos do que esses trezentos e cinquenta, se tiver trezentos e cinquenta, não pode receitar pra tomar o remédio'. O meu tá quatrocentos e oitenta..." (Nega, gay, 32 anos).

Os resultados da pesquisa mostram a necessidade de se ampliar o acesso aos serviços de saúde para este segmento, o que implica os desafios já descritos anteriormente por outros autores, tanto pela situação de rua quanto pela homo/bi/ transexualidade desta população. No caso da situação de rua, a promoção do acolhimento deste segmento deve favorecer a vinculação ao serviço de saúde; combatendo as normas burocráticas de muitas instituições de saúde, que envolvem a exigência de documentos de identificação e de comprovação de moradia e superando a resistência dos profissionais de saúde, principalmente em relação à higiene considerada inadequada por parte de muitas das pessoas em situação de rua (Carneiro et al., 1998; Dantas, 2007). Mas existem barreiras de várias ordens também relacionadas à aceitação das homo/bi/transexualidades, que passam também pela discriminação no atendimento propriamente dito, como pode ser visto, por exemplo, no desrespeito demonstrado pela não utilização do nome social entre travestis e mulheres transexuais, e a falta de atenção a especificidades de sua saúde para além do campo das DSTs e AIDS, como é o caso apontado por Terto (2002), referente aos agravos à saúde mental motivados pela discriminação sofrida.

No caso específico do HIV/AIDS, é importante a ampliação do acesso aos serviços de testagem, aconselhamento e tratamento quando necessário à população LGBT de rua. No caso da terapia antirretroviral, a parceria com as instituições de outros setores voltadas ao atendimento deste segmento, como os albergues e casas de convivência, se apresenta como uma estratégia indispensável para se garantir a continuidade do tratamento.
O caráter nômade da população estudada reforça a necessidade de ampliação das Equipes de Saúde da Família específicas para este segmento e suas necessidades (Carneiro, Jesus, \& Crevelim, 2010) e de implantação nas grandes cidades de programas para a atenção ao abuso de substâncias psicoativas nos moldes dos "Consultórios de Rua" (Nery \& Valério, 2010), que se constituem como unidades móveis com equipes multiprofissionais para prestar assistência neste campo, usualmente adotando a redução de danos como uma das estratégias centrais.

\section{Conclusão}

A análise das trajetórias de vida dos informantes de rua evidenciou a presença de uma forma de sociabilidade nômade, associada ao afastamento de vínculos com as instâncias trabalho, família e escola, à vivência nas ruas e ao uso frequente de substâncias psicoativas. Embora este tipo de sociabilidade possa ser relacionado ao contexto de preconceito heterossexista nas famílias, escolas e ambientes de trabalho, as trajetórias destas pessoas mostram também a resistência aos ideais de fixação presentes nestas instituições, o que requer a atenção dos formuladores de políticas públicas em relação ao conhecimento e respeito necessários para que a atenção direcionada a este segmento não vise aplacar as singularidades destas trajetórias.

O conceito de vulnerabilidade mostrou-se operativo para o entendimento das dificuldades relatadas pelos pesquisados, especialmente por permitir estabelecer o cruzamento de suas trajetórias individuais com as formas de dominação heterossexistas presentes em diversos contextos da sociedade brasileira e com a relativa ausência de ações programáticas voltadas a este segmento. A atenção às vulnerabilidades diversas observadas situa-se como decorrência do reconhecimento pleno dos direitos humanos previstos na legislação brasileira, mas deve implicar, como observado, o reconhecimento do direito às formas de sociabilidade que rompam com o ideal da vida burguesa e carreguem consigo a marca da vida na noite e nos espaços públicos, da moradia incerta, dos relacionamentos fortuitos, do uso de 
substâncias psicoativas e do frequente recurso ao mercado sexual.

Em relação ao HIV/AIDS, este estudo mostra que a vida nas ruas configura-se como uma situação onde se acumula uma sinergia de situações de discriminação e violência que, fortemente relacionadas entre si, aumentam a vulnerabilidade à infecção pelo HIV e ao adoecimento por AIDS.

As trajetórias de muitos dos informantes desta pesquisa evidenciam que o preconceito e a discriminação associados a orientações sexuais e identidades de gênero dissidentes são elementos predisponentes para a situação de rua por eles vivenciada, dada sua forte presença nas instituições familiares, escolares e laborais, dificultando o apoio familiar nas situações de crise financeira e o recurso a empregos de melhor remuneração, o que favorece por sua vez a inserção no mercado sexual. Estas trajetórias somadas à violência homofóbica nas ruas, ao uso abusivo de drogas e à vulnerabilidade programática resultante da precariedade das políticas de assistência na área em que circulam mostraram-se como elemento intimamente associados ao aumento da vulnerabilidade ao HIV/AIDS.

Para além da vulnerabilidade social e individual à infecção presumidamente muito aumentada neste segmento por conta do contexto acima descrito, as descrições densas obtidas nas entrevistas permitiram observar a dificuldade em relação a se seguir o tratamento adequado, em especial quando envolve o uso de antirretrovirais, devido principalmente às vivências nômades deste segmento, o que dificulta tanto a frequência aos serviços de saúde quanto a guarda adequada dos medicamentos a serem utilizados.

Políticas públicas que considerem a especificidade deste segmento, tanto na área da saúde quanto na da educação, habitação e assistência social, devem levar em consideração o caráter nômade das vivências destas pessoas. Esse caráter nômade interpela a propriedade dos processos de trabalho de cuidado e atenção psicossocial que ainda dominam a formação curricular do psicólogo (centrado na clinica individual e ambulatorial) ou as teorias psicológicas descontextualizadas comuns nos cursos da área de medicina, enfermagem, assistência social e pedagogia.

\section{Referências}

Ayres, J. R., França, I., Jr., Calazans, G. J., \& Salleti, H. C., Filho (1999). Vulnerabilidade e prevenção em tempos de AIDS. In R. M. Barbosa \& R. Parker (Orgs.), Sexualidades pelo avesso: $\mathrm{Di}$ reitos, identidades e poder (pp. 49-720). Rio de Janeiro, RJ: Editora 34.

Bardin, L. (2004). Análise de conteúdo. Lisboa, Portugal: Edições 70.

Brito, V. O. C., Parra, D., Facchini, R., \& Buchalla, C. M. (2007). Infecção pelo HIV, hepatites B e $\mathrm{C}$ e sífilis em moradores de rua, São Paulo. Revista de Saúde Pública, 41(2), 47-56.

Bux, D. A. (1996). The epidemiology of problem drinking in gay men and lesbians: A critical review. Clinical Psychology Review, 16(4), 277298.

Carneiro, N., Jr., Jesus, C. H., \& Crevelim, M. A. (2010). A Estratégia Saúde da Família para a equidade de acesso dirigida à população em situação de rua em grandes centros urbanos. Saúde e Sociedade, 19(3), 709-716.

Carneiro, N., Jr., Nogueira, E. A., Lanferini, G. M., Ali, D. A., \& Martinelli, M. (1998). Serviços de saúde e população de rua: Contribuição para um debate. Saúde e Sociedade, 7(2), 47-62.

Cochran, B. N., Stewart, A. J., Ginzler, J. A., \& Cauce, A. M. (2002). Challenges faced by homeless sexual minorities: Comparison of gay, lesbian, bisexual, and transgender homeless adolescents with their heterosexual counterparts. American Journal of Public Health, 92(5), 773-777.

Costa, A. P. M. (2005). População em situação de rua: Contextualização e caracterização. Textos \& Contextos, 4(1), 1-15.

Dantas, M. (2007). Construção de políticas públicas para população em situação de rua no município do Rio de Janeiro: Limites, avanços e desafios (Dissertação de mestrado, Escola Nacional de Saúde Pública, Rio de Janeiro, RJ, Brasil).

De Lucca, D. (2007). A rua em movimento - Experiências urbanas e jogos sociais em torno da população de rua (Dissertação de mestrado, Faculdade de Filosofia, Letras e Ciências Humanas, Universidade de São Paulo, SP, Brasil). 
Deleuze, G., \& Guattari, F. (1995). Mil platôs: Capitalismo e esquizofrenia (Vol. 5). São Paulo, SP: Editora 34.

Dunne, G. A., Prendergast, S., \& Telford, D. (2002). Young, gay, homeless and invisible: A growing population? Culture, Health \& Sexuality, 4(1), 103-115.

Escorel, S. (1999). Vidas ao léu: Trajetórias de exclusão social. Rio de Janeiro, RJ: Fundação Oswaldo Cruz.

Frangella, S. M. (2004). Corpos urbanos errantes: Uma etnografia da corporalidade de moradores de rua em São Paulo (Tese de doutorado, Instituto de Filosofia e Ciências Humanas, Universidade Estadual de Campinas, SP, Brasil).

Green, J. N. (2000). Além do Carnaval: A homossexualidade masculina no Brasil do século $X X$. São Paulo, SP: Universidade Estadual Paulista Júlio de Mesquita Filho.

Guattari, F. (1992). Caosmose: Um novo paradigma estético. São Paulo, SP: Editora 34.

Hall, S. (2003). A identidade cultural na pós-modernidade. Rio de Janeiro, RJ: DP\&A.

Hyde, J. (2005). From home to street: Understanding young people's transitions into homelessness. Journal of Adolescence, 28(2), 171-183.

Meta Instituto de Pesquisa de Opinião. (2008). Relatório final do primeiro censo nacional e pesquisa amostral sobre a população em situação de rua. Porto Alegre, RS: Autor.

Joint United Nations Programme on HIV/AIDS. (2006). Report on the global AIDS epidemic. Geneva, Switzerland: Author.

Jordan, K. M. (2000). Substance abuse among gay, lesbian, bisexual, transgender, and questioning adolescents. School Psychology Review, 29, 201-206

Kennedy, M. (1991). Homeless and runaway youth mental health issues: No access to the system. Journal of Adolescent Health, 12, 576-579.

Kipke, M. D., O’Connor, S., Palmer, R., \& Mackenzie, R. G. (1995). Street youth in Los Angeles: Profile of a group at high risk for human immunodeficiency virus infection. Archives of Pediatrics \& Adolescent Medicine, 149(5), 513-519.

Kruks, G. (1991). Gay and lesbian homeless/street youth: Special issues and concerns [Special issue]. Journal of Adolescent Health, 12(7), $515-$ 518 .
Lovisi, G. M. (2000). Avaliação de distúrbios mentais em moradores de albergues públicos das cidades do Rio de Janeiro e Niterói (Tese de doutorado, Escola Nacional de Saúde Pública, Fundação Oswaldo Cruz, Rio de Janeiro, RJ, Brasil).

Maffesoli, M. (2001). Sobre o nomadismo: Vagabundagens pós-modernas. Rio de Janeiro, RJ: Record.

Malta, M., Petersen, M. L., Clair, S., Freitas, F., \& Bastos, F. I. (2005). Aderência à terapia anti-retroviral: Um estudo qualitativo com médicos no Rio de Janeiro. Cadernos de Saúde Pública, 21(5), 1424-1432.

Milburn, N. G., Ayala, G., Rice, E., Batterham, P., \& Rotheram-Borus, M. J. (2006). Discrimination and exiting homelessness among homeless adolescents. Cultural Diversity and Ethnic Minority Psychology, 2(4), 658-672.

Nery, A., Filho, \& Valério, A. L. R. (Orgs.). (2010). Módulo para capacitação dos profissionais do projeto consultório de rua. Brasília, DF: Secretaria Nacional de Políticas sobre Drogas.

Parker, R. (2002). Abaixo do Equador. Rio de Janeiro, RJ: Record.

Pennbridge, J. N., Freese, T. E., \& Mackenzie, R. G. (1992, Fall). High-risk behaviors among male street youth in Hollywood, California. AIDS Education and Prevention (Suppl.), 24-33.

Perlongher, N. (1987). O negócio do michê: Prostituição viril em São Paulo. São Paulo, SP: Brasiliense.

Perrot, M. (2009). Maneiras de morar. In P. Ariés \& G. Duby (Orgs.), História da vida privada: Da Revolução Francesa à Primeira Guerra (Vol. 4, pp. 284-302). São Paulo, SP: Cia. das Letras.

Pfeifer, R. W., \& Oliver, J. (1997). A study of HIV seroprevalence in a group of homeless youth in Hollywood, California. The Journal of Adolescent Health, 20(5), 339-342.

Rew, L., Whittaker, T. A., Taylor-Seehafer, M. A., \& Smith, L. R. (2005). Sexual health risks and protective resources in gay, lesbian, bisexual, and heterosexual homeless youth. Journal for Specialists in Pediatric Nursing, 10(1), 11-19.

Rosenthal, D., Mallett, S., \& Myers, P. (2006). Moving out moving on: Young people's pathways in and through homelessness in Melbourne. Australian and New Zealand Journal of Public Health, 30(3), 281-285. 
Rotheram-Borus, M. J., \& Koopman, C. (1991). Sexual risk behaviors, AIDS knowledge, and beliefs about AIDS among runaways. American Journal of Public Health, 81(2), 208-210.

Silva, L. A. (2000). Cartografia da atenção à saúde da população de rua na cidade de São Paulo: Um estudo exploratório (Dissertação de mestrado, Pontifícia Universidade Católica de São Paulo, SP, Brasil).

Sondheimer, D. L. (1992). HIV infection and disease among adolescents. In R. J. Diclemente (Ed.), Adolescents and AIDS: A generation in jeopardy (pp. 71-85). Newbury Park, CA: Sage.

Souza Santos, B. (1997). Por uma concepção multicultural de direitos humanos. Lua Nova - Revista de Cultura e Política, 39, 105-124.

Sugerman, S. T., Hergenroeder, A. C., Chacko, M. R., \& Parcel, G. S. (1991). Acquired immunodeficiency syndrome and adolescents. Knowledge, attitudes, and behaviors of runaway and homeless youth. American Journal of Diseases of Children, 145(4), 431-436.
Terto, V., Jr. (2002). Homossexualidade e saúde: Desafios para a terceira década de epidemia de HIV/AIDS. Horizontes Antropológicos, 17, 147-158.

Unger, J. B., Kipke, M. D., Simon, T. R., Montgomery, S. B., \& Johnson, C. J. (1997). Homeless youths and young adults in Los Angeles: Prevalence of mental health problems and the relationship between mental health and substance abuse disorders. American Journal of Community Psychology, 25(3), 371-394.

Whitbeck, L. B., Chen, X., Hoyt, D. R., Tyler, K., \& Johnson, K. (2004). Mental disorder, subsistence strategies, and victimization among gay, lesbian, and bisexual homeless and runaway adolescents. The Journal of Sex Research, 41(4), 329-342. 